$$
2 \sqrt{5}-31
$$

\title{
青海湖流域近六百年来的气候变化 与湖水位下降原因
}

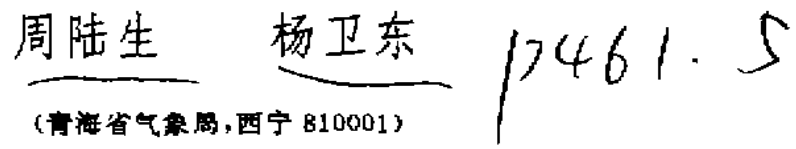

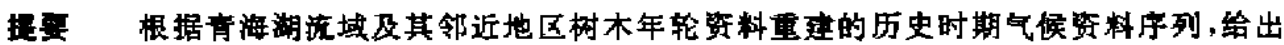

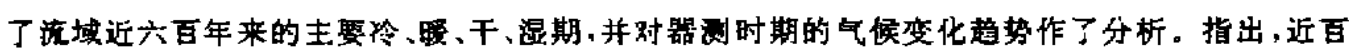
年来气候煖于化是造成湖水位下降的声要原图; 对于湖水位年䏡变化与前期降水影响系统、不 同气候类型以及地面要毒的关系作了统计分析.

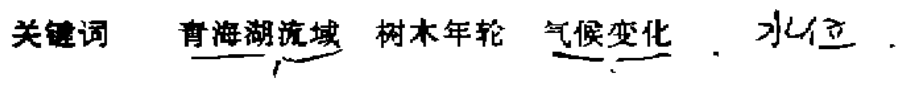

青海湖有水文记录以来一个明显的观测事实是: 湖水位平均年以 $10.2 \mathrm{~cm}(1959$ 1988 年 的速度急剧下降。已有研究 ${ }^{2}$ 表明, 人为活动直接总耗水量只占湖水平均亏损量的 $8.7 \%$. 所以人为直接耗水不是湖水位下降的主要原因。从目前的工作看.湖水位的变化主要 受气候、水文等环境因索的综合影响,而气候的长期变化和短期波动则是引起水位变化的最 重要的原因。

\section{一、历史时期的气候变化}

青海湖流域几百年来的气候变化研究因缺乏长期观测资料和文献记载,所以本文主要 采用树木年轮方法来重建气校资料序列，划分主要的冷、暖、千、湿期，而用邻近边区的历史 文献资料来印证研究的主要结果。

\section{(一)树木年轮序列}

1. 样木及奴理

1986 、1988 年夏和 1989 年初我们在青海湖流域及邻近林区进行采样, 同时还采集了一 些玨立木的样本。采集的树种主要是祁连圆柏,共采得 49 椤树, 92 个样本、各采集点均采复 本。采样点及流域邻近地区的气象站位置见表 1 。

从表 1 平均敏感度 $\left(M \cdot S=\frac{1}{n-1} \sum_{0}^{n-1}\left|\frac{2\left(X_{i+1}-X_{0}\right)}{X_{0+1}+X_{i}}\right|, X_{1}\right.$ 为年轮宽度, $n$ 为年轮总 数)栏可以看出,样本包含的大气候信息比较丰富 $(M \cdot S>0.2)$, 年代也较长.最长的可达

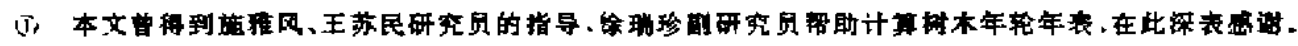

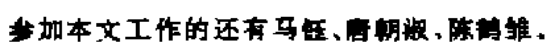

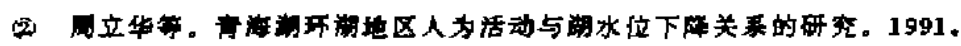




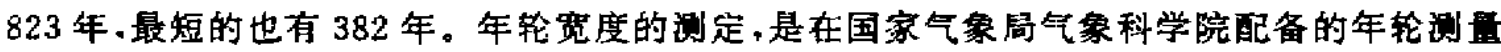
系统上完成。关于树朴生长量的订正,由于每个样木的订正表达式及待定系数都不尽相同， 在此不再一一给出。

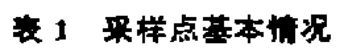

Tab. 1 Basic conditions of sampling spots

\begin{tabular}{|c|c|c|c|c|}
\hline 地 点 & 经纬度 & 拔(m) & $\begin{array}{c}\text { 起止年代 } \\
\text { (按地长树) }\end{array}$ & 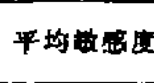 \\
\hline 邦 连 & $\begin{array}{l}38^{\circ} 0 T^{\prime} N \\
100^{\circ} 2 d^{\prime} E\end{array}$ & $3350-3400$ & $1414-1985$ & 0.220 \\
\hline 帛 兰 & $\begin{array}{l}37^{\circ} 03^{\prime} \mathrm{N} \\
98^{\circ} 31^{\prime} \mathrm{E}\end{array}$ & $3600-3700$ & $1163-1985$ & 0.283 \\
\hline 天吺萧汗诺 & $\begin{array}{l}37^{\circ} 05^{\prime} \mathrm{N} \\
99^{\circ} 00^{\prime} \mathrm{E}\end{array}$ & $3600-3700$ & $125 B-1988$ & 0.450 \\
\hline 语湖石乃药 & $\begin{array}{l}36^{\circ} 48^{\prime} \mathrm{N} \\
99^{\prime} 35^{\prime} \mathrm{E}\end{array}$ & $3500-3600$ & $1607-1989$ & 0.286 \\
\hline
\end{tabular}

经生长粗订正之后,便可得到每个样本的年轮指数: $I_{r}=\frac{R_{t}}{Y_{t}}$. 式中 $R_{r}$ 为树轮的宽度. $Y$, 为生长量订正值。将 $I_{r}$ 按样木点求和。求得各个采集点的平均年轮指数序列即所谓年表。

\section{2. 相关性分析}

乌兰、察汗诺、石乃亥都与柴达木盆地东部相邻、風于干旱和半干旱气候类型,这些地方 的树木生长状况的主要限制因子是降水; 衩连属于凉温半湿润气候类型，热量状况决定着树 木的生长状况。4 个采样点的年轮指数与流域内及邻近地区气象站 30 年左右的降水、气温 相关分析揭示了这种关系（表 2、3)，可以看出，绝大多数都存在著正相关关系，而且不少都 达到一定的显著性标准。由此，我们可以依据相关方珪来重建流域的气候资料序列。

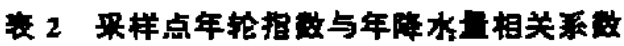

Tab. 2 Correlation coeffikients between prectpitution and

tree ring lndex on the sampling spots

\begin{tabular}{|c|c|c|c|c|c|c|c|c|c|c|c|c|c|c|}
\hline \multirow{2}{*}{ 样 } & \multirow[b]{2}{*}{ 点 } & & \multicolumn{2}{|l|}{ 碑 } & \multicolumn{2}{|c|}{ 天 城 } & \multicolumn{2}{|c|}{ 箃 兰 } & \multicolumn{2}{|c|}{ 江西鸧 } & \multicolumn{2}{|c|}{ 比卜加 } & \multicolumn{2}{|c|}{ 海 } \\
\hline & & & $\boldsymbol{R}$ & $\boldsymbol{R}^{\prime}$ & $\boldsymbol{R}$ & $R^{\prime}$ & $R$ & $R^{\prime}$ & $R$ & $\boldsymbol{R}^{\prime}$ & $\boldsymbol{R}$ & $\boldsymbol{R}^{\prime}$ & $\boldsymbol{R}$ & $\boldsymbol{R}^{r}$ \\
\hline 官 & & 兰 & 0.289 & 0.318 & 0.206 & 9.255 & $10,364^{\circ}$ & $0.370^{\circ}$ & $0.382^{\circ}$ & 0.323 & 0.032 & 0.233 & 0.300 & 0.009 \\
\hline * & if & it & $0.389^{-}$ & 0.337 & $0.434^{\circ}$ & 0.299 & 0.127 & -0.020 & 0.291 & 0.324 & 0.217 & 0.231 & 0.192 & 0.021 \\
\hline 石 & 3 & 齐 & 0. $551^{*}$ & 0.141 & -0.005 & -0.036 & 0.194 & 0.204 & 0.343 & 0. 226 & 0.285 & -0.010 & 0.252 & 0.147 \\
\hline
\end{tabular}

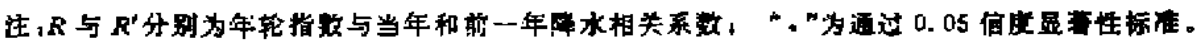

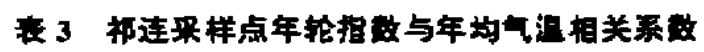

Tab. 3 Correlution coeffjeients between anapial mean air temperature and tree ring Index on the sampling spots

\begin{tabular}{|c|c|c|c|c|c|c|c|c|c|c|c|c|}
\hline 气釷站 & 剿 & 茶 & 天 & 唼 & & 迋 & 讧 & 西福 & t & 下如 & 每 & 5 \\
\hline \multirow{2}{*}{ 相决系较 } & $R$ & $R^{\prime}$ & $R$ & $R^{\prime}$ & R & $R^{\prime}$ & $R$ & $R^{\prime}$ & $\boldsymbol{R}$ & $R^{\prime}$ & $\bar{R}$ & $\boldsymbol{R}^{\prime}$ \\
\hline & $0.499^{\circ}$ & 0.237 & 0.259 & 1). 121 & a. 165 & $0.418^{\circ}$ & $0.381^{\circ}$ & $0.436^{\circ}$ & $0.397^{\circ}$ & $0.371^{\circ}$ & 0.318 & 0.157 \\
\hline
\end{tabular}

*高为同 2

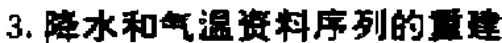

可以用来饭复降水资料序列的年表有 3 个, 由于言兰年表样本数多达 24 个,且年表长 
823 年,因此资料的可靠性、连续性方面梳于其它 2 个年表。故分别用衫连和乌兰年表坆复 青海湖流域历史时期的温度和降水资料序列。根据有关方程可以换算成距平序列，并作 50 年滑动平均,以分辩主要的气候变化时期。

分别对重建的温度和降水序列作功率谱分析，得出温度序列有在着 2.1、2.4、3.0、75、 100.150 年等显著周期, 而降水序列具有 $2 、 80 、 100 、 133$ 年的显著周期。

\section{(二)主要冷暖干湿期}

[图 1 为青海湖流域冷暖于湿期演变状况。可以看出,近六百年来青海湖流域大约有 5 个 相对温暧和 4 个相对寒冷的时期。其中主要的温暖期是在 16 世纪、18 世纪末到 19 世纪前 半期; 主要的寒冷期是在 15 世纪后半期、17 世纪 40 年代到 18 世纪 30 年代。等可㮌对于公 元 1400-1900年这五百年的气候变化曾指出 ${ }^{[1]}$ : “温暖的冬季是在公元 1550-1600 年和 $1770-1830$ 年间。寒冷的冬季是在公元 1470--1520、1620-1720 和 $1840-1890$ 年间。”这 分别与青海湖流域公元 $1513-1603 、 1787-1850$ 年的暖期和 $1448-1512 、 1647-1737$ 、 $1851-1880$ 年的冷期相对应。

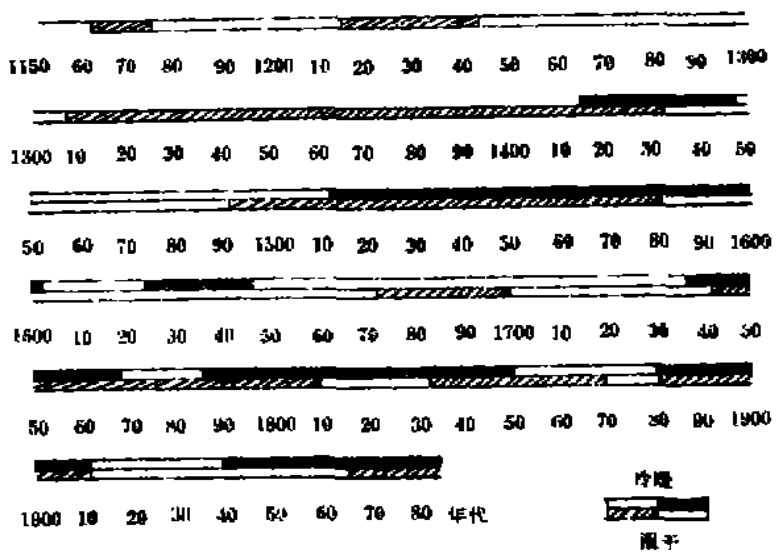

图 1 海湖流域玲、暖、干、湿期

Fig. 1 Cold, warm,dry and wet periods in Qinghai Lake Basin

青海湖流域八百多年来大体上可分为 4 个相对湿润期和 4 个相对千燥期。千燥期为: $1176-1308 、 1433-1492 、 1582-1742$ 和 $1913-1966$ 年; 湿润期为: $1309-1432 、 1493-$ $1581 、 1743$ - 1912 年和 1967 年以后。

据史料记记载, 1582--1742 年共有灾情 24 条、其中早象记载占总条数的 $45.8 \%$,饬的 记载只占 $12.5 \%$,其余为大风、低温、虫灾和管灾等记载, 可见这一时期以旱象居多。17431912 年有关记载共 52 条,其中雨涝、洪灾占 $44.2 \%$. 丰年占 $26.9 \%$, 早年仅占 $11.5 \%$,其它 占 $17.4 \%$, 可见这段时期降水偏多.主要矛盾是“洪漟”。1913-1966 年间.有关音海东部地 区的记载丰富而又详细、揬旱港等级划分、除正常年景外, 旱与编旱等级年份为港与偏漟等 级年份的 1.53 倍。可见这一时期的编旱占有一定的优势。

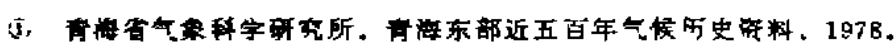


由以上史料印证情况看、用树木年轮资料划分的干湿期是可信的。综上所述,育海湖流 域近六百年来的主要冷暖干湿期大致为: 15 世纪中、后期为冷干期:16 世纪以煖湿期为主; 17 世纪到 18 世纪前期以冷干年份居多; 18 世纪中期到 20 世纪初又以暖湿为主导; 20 世纪 前期以冷干为主.中期转为㖟干，从 60 年代末至今基本维持举䁔湿的气候。初略估计、这期 间平均气温的绝对变化大约不勋过 $1 \mathrm{C}$,年平均降水量变化不超过 $50 \mathrm{~mm}$ 。

\section{二、器测时期的气候诊断分析}

考虑到气象记录的长度和完整性,并兼顾到各个方位,在高海湖流域及邻近地区选刚

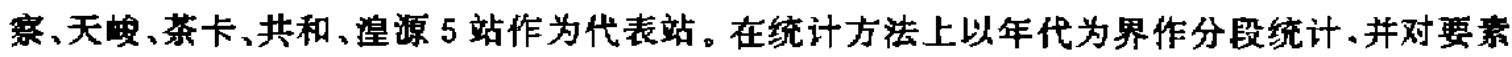
作平滑处理 (9 年滑动平均) 如表 4、图 2。理分别讨论气温、降水、蒸发变化趋势。

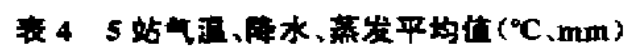

Tab. 4 Average values of air temperature, precipitation and evaporation of tive stations

\begin{tabular}{|c|c|c|c|c|c|c|c|}
\hline 项 目 & 年平姆 & 1月平妁 & 7月平均 & 气目年 & $\geqslant 00$ & 年 & 年 䔍 \\
\hline 年 & 嗢 & 气温 & 도 & 较 堂 & 积 & 水 4 & 堅 \\
\hline $1958-1960$ & 1.1 & -12.7 & 13.5 & 26,2 & 1705 & 338.0 & 1855.2 \\
\hline $1961-1970$ & 1.0 & -12.9 & 13.0 & 25.9 & 1735 & 332,0 & 1729.2 \\
\hline $1971-1980$ & 1.4 & -12.4 & 12.8 & 25.2 & 1769 & 312. ? & 1691.5 \\
\hline $19 B 1-19 B B$ & 1. 3 & -11.6 & 12.8 & 24.4 & 1716 & 347.8 & 1608.9 \\
\hline
\end{tabular}

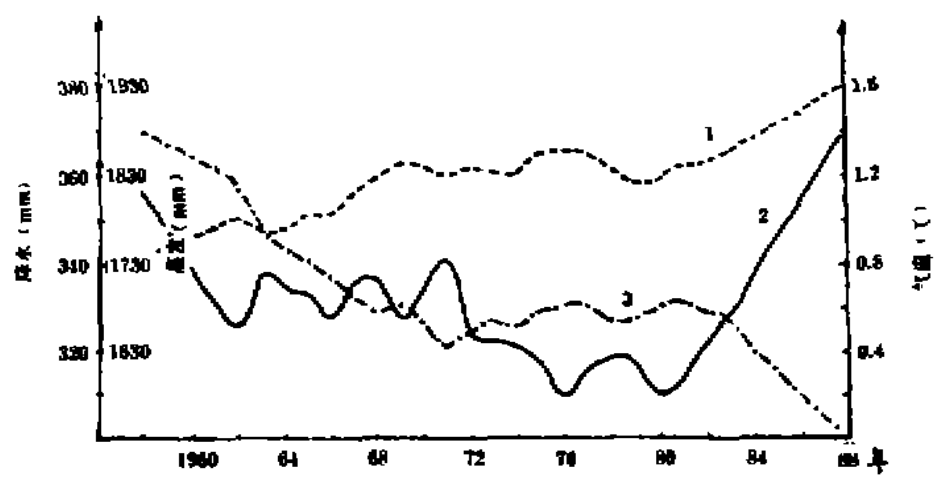

图 2 刚寀等 5 站年平均温、降水、蒸发滑动平均曲线

1. 温, 2. 䧏水. 3. 蒸发

Fig. 2 Running average curves of annual mean air temperature, precipitation and eraporation of five stations.

\section{1. 鼔}

青海湖流域 30 多年来平均气温呈上升美势,冬季气温(包括极端最低气温,表 4 中末列 出)增高明显，夏季气温(包括极端最高气温,表 4 末列出)出现下降趋势。冬变暖而夏转倞的

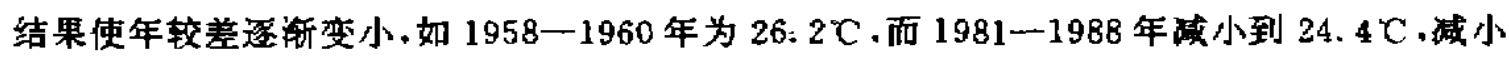
了 $1.8^{\circ} \mathrm{C}$ 。 
2. 降水

60 年代以前降水比较平稳.进入 70 年代相对偏少.从 80 年代开始哇明显上升趋势。综 合温度、降水状况,可以看出从 80 年代开始气候有向䁔湿方向发展的趋势。

3. 蒸发

蒸发总趋势是在下降, 1981-1988 年比 1958-1960 年5 站平均值要娍少 $246.3 \mathrm{~mm}$, 其 中茶卡、共和减少更为明显, 减少量分别为 $470 \mathrm{~mm}$ 和 $385 \mathrm{~mm}$. 这相当于两站年平均雨量的 2.3 倍和 1.2 倍。蒸发与降水在 80 年代之前, 两者几乎同时下降.但到 70 年代末开始两者 变化趋势相反。几乎在同一时期开始温度与蒸发亦表现为相反的变化趋势。造成这种现象 的原因主要有两点: (1)年平均气温虽然升高, 但在蒸发最旺盛的夏季气温反而降低,故总效 应还是使蒸发量减少; (2)80年代这几年的平均风速几乎均为负化平、比平均值减小 $0.3-$ $0.5 \mathrm{~m} / \mathrm{s}$, 这也使得蒸发量减小。

\section{三、湖水位变化的气象因素}

湖水位变化由长时期的变化趋势和年际变化两部分组成。下文分别讨论一百多年来湖 水位下降刍势以及器测时期水位年际变化形成的气象因亲。

\section{（一)湖水位下降捔势的原因}

根据树木年轮重建的气候资料序列，从1881年至 1985 年共 105 年间，暖期 77 年，冷期 28 年,干期 55 年,湿期 50 年。所以暖是百年来主要气候特征,其次是干略占优势。施雅风根 据亚洲中部山区冰川进退变化和物质平衙观测以及受人类活动影响较小的山区湖泊萎缩资

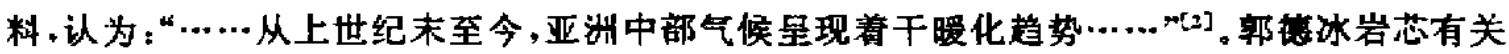
资料显示 ${ }^{[3]}: 20$ 世纪为暖期.其起始时间大约在 19 世纪末。本文用树木年轮资料反映的青 海湖流域一百多年的气候变化以暖偏干为主要趋势与上述结论基本一致。

以暖干为主要特征的气候背景。造成湖面蒸发量超过湖面降水量与人湖远流量之和，因 而形成湖水均衡亏损量累计值道增的趋势,这是百年来湖水文的基本特征。据有关资料推 算 ${ }^{[2]}, 1908$ 年至 1957 年水位下降率 $17.2 \mathrm{~cm} / \mathrm{a}$, 蓓水量减少率 $8.21 \times 10^{8} \mathrm{~m}^{3} / \mathrm{a}$, 湖面积减少 率 $8.4 \mathrm{~km}^{2} / \mathrm{a}$ 。有记录以来,自 1956 年至 1988 年, 水位下降了 $3.35 \mathrm{~m}$, 累计亏水量 $148.13 \times$ $10^{8} \mathrm{~m}^{3}$, 湖水面积娍少 $301.6 \mathrm{~km}^{2}$ 。事实上,湖水位变化曲线与湖水亏损量(根据水均街原理实 际测算得到的每年亏损量)暴计值曲线几乎完全㕫合(图略)。因此,可以认为因气候㖟干化 导致湖水量入不抵支的长期发展是形成湖水位下降趋势的根本原因。

\section{（二）湖水位年际变化的原因}

\section{1. 水位异常变化前期的降水影响系统}

表 5 为水位年际变化及相应年份气候类型划分结果。由于水位年际变化与前一年雨季 5-9 月降水密切相关.因此普查该时段的高空、地面天气图、以寻找青海湖流域主要降水影 响系统。统计表明,青海湖过境冷锋或钿贝锋、柴达木槽、黑河低涡或橧是流域主要降水影响 系统,柴达木盆地和黑河是两个关键地区。

1968 年水位回升最多达 $32 \mathrm{~cm}, 1979$ 年水位下降次多达 $33 \mathrm{~cm}$ 。分别以这两年作为水位 异常升、降年、统计影响系统出现制率之差异。结果表明,锋面、柴达木槽、黑河低涡或掼回升 年比下降年分别增加了 $69 \% 、 108 \%$ 和 $72 \%$, 差异十分显著。另外取 $1961 、 1970 、 1974 、 1979$ 、 1980 年为水位异常下降组.1968、1972、1976、1982、1983 年为水位回升年组.统计两组前一 
年 5-9 月 $500 \mathrm{hPa}$ 高度距平合计值。可以明显看出－在回升年整个背藏高原至帕米尔高原 为一致的大范围负距平区,而下降年为正距平区 (图略)。

部 5 水位年际变化与气㜔类型划分

(单位: cm)

Tab. 5 Annugl variation of lake water level and classification of climatic pattern

\begin{tabular}{|c|c|c|c|c|c|c|c|c|c|c|c|c|c|c|c|c|}
\hline 年 形 & 1958 & 1959 & 960 & 1961 & 1962 & 1963 & 1964 & 2965 & 1866 & 1067 & 1968 & 1969 & 1970 & 1971 & 1972 & 1973 \\
\hline 水位变化 & & & -23 & -24 & -17 & -15 & -1 & -3 & -17 & 18 & 32 & -19 & -26 & -15 & 3 & \\
\hline 搌类蒰 & NS & $\mathrm{LG}$ & $\overline{L G}$ & LG & LG & L.G & LS & LG & NG & LS & LG & $N G$ & 1.6 & $\overline{N S}$ & $\mathrm{NS}$ & NG \\
\hline 年 $\quad 0$ & 1974 & 1975 & 1976 & 1977 & 1978 & 1979 & 1980 & 1981 & 1982 & 1983 & 1984 & 1985 & 1986 & 1987 & 1988 & \\
\hline 位变化 & -26 & 0 & 4 & -14 & -11 & -33 & -34 & -21 & 2 & 9 & & -22 & -4 & -8 & -11 & \\
\hline 搌类罚 & LS & LS & LS & LG & NG & ViG & NG & NS & LG & IS & LG & NS & $\overline{L S}$ & NS & NS & \\
\hline
\end{tabular}

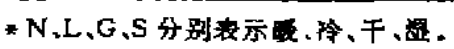

\section{2. 不同电娭型对水位年际变化的影响}

选取天的、刚察、海晏、茶卡 4 站为代表站, 以 4 站年平均气温距平合计值和年降水量距 平百分率之和作为划分冷、瞹和干、湿的指标 (正值为暖、湿、负值为冷、干)、组成的气娭类型 见表 5。表 6 为不同气候型下造成示位升、降的统计结果。由表 5、表 6 可以看出：(1) 就总 的平均晴况而言, 偏干年份伴随着水位的一致下降, 其中暧干年下降幅度最大; 偏湿年份只 有暧湿年可使当年水位下降、其余可使水位略有上升或持平,其中冷湿年最有利于水位回 升。由于降水对水位影响的滞后性、湿润状况对水位的影响在下一年体现得更明显、而冷热 状况对当年水位的影响更直接些; (2)绝大多数水位上升年的前一年都偏漣，几乎所有偏干 年份的第二年水位均下降；(3)水位年际变化主要取决于上年气娭类型,但也与当年气候状 况有关。例如 1967,1983 年这两年当年流域温度距平一为历年负距平最大和次大, 1967 年降 水量为历年最大值.1983 年也为正距平、因此两年都筬冷湿型,使水位回升。

表 6 气楼类型与湖水位升降(1960－1988 年)

\{单位: $\mathrm{cm}$ )

Tab. 6 Climatic pattern and fluctuation of lake water level (1960-1988)

\begin{tabular}{|c|c|c|c|c|c|c|c|c|c|}
\hline \multirow{2}{*}{ 弮 鼍 } & \multirow{2}{*}{\multicolumn{2}{|c|}{ 年 }} & 水 & \multirow{2}{*}{ 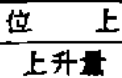 } & 升 & 水 & \multirow{2}{*}{$\frac{\text { 位 }}{\text { 下象 }}$} & 降 & \multirow{2}{*}{ 年平均 } \\
\hline & & & 年 伤 & & 平坞 & 年 仿 & & 平 坞 & \\
\hline 晈平 & & 晃年 & & & & 6 & 135 & 22.5 & $-22,5$ \\
\hline$(N G) !$ & 0 & 年年 & 1 & 18 & 18.0 & 5 & 140 & 28.0 & $-20,3$ \\
\hline 冷平 & 2 & 当年 & 3 & 35 & 11.7 & 7 & 122 & 17.4 & -8.7 \\
\hline (LG) & & 厎年 & 1 & $y$ & 9.0 & 9 & 141 & 15.7 & -13.2 \\
\hline 樶潼 & & 嘗年 & 1 & 3 & 3.0 & 5 & 77 & 15.4 & -12.3 \\
\hline (NS) & & 下年 & 3 & 38 & 12.7 & 3 & 36 & 12.0 & 0,3 \\
\hline 跉粟 & & 当年 & 4 & $\overline{3} \bar{I}$ & 7.8 & 3 & 31 & 10.3 & 0,0 \\
\hline (LS) & & 下年 & 4 & $3 T$ & 9.3 & 3 & 25 & 8. 3 & 1.7 \\
\hline
\end{tabular}

\section{3. 主要地面气象要素与水位年际棸化的关系}

青海湖属于封闭的内陆湖泊，从湖水量平衡原理出发，考虑可能影响水位年际变化的各 项气象因子及其各因子某些综合共计 24 项,采用逐步回归方法来评价各因子对湖水位年际 变化的贡裁。结果表明.虽然在不同门限时的入选因子有所差异,但蒸发量、垉和差和上一年 降水量始终是主要的影响因子。青海湖流域及邻近地区 8 个气象站 (刚察、天畯、荣卡、江西 沟、共和、海晏、湟源、玟连)年平均气温 $(T)$ 、年蒸发总量 $(L)$ 和上一年降水总量 $(R)$ 与水位 年际变化 $(Y)$ 的相关系数分别为 $-0.405 、-0.608,0.539$. 均通过信度取 0.01 的显著性 标准。将上述三要素连行标准化处理. 并组成综合指标 $S=\frac{R}{T-L}$. 经计算 $S$ 与 $Y$ 相关系数为 0.703. 
利用单站前期要素来预测水位年际变化效果良好,兹举刚察为例：

$$
Y=-0.0095-0.1352 \Delta T+0.006 \Delta R
$$

式中 $\Delta T 、 \Delta R$ 分别为该站前一年平均气温距平和雨季 $5-9$ 月降水量距平。上式显著性㭘验 $F=10.27>F_{0.01}$ 。

\title{
四、结论
}

1. 青海湖流域近六百年来主要暧湿期为 16 世纪、18 世纪中期到 20 世纪初期; 主要的 冷干期为 15 世纪中、后期以及 17 世纪到 18 世纪前期。最近的一百多年流域气候暖偪干.本 世纪 40-60年代较明显.80 年代初开始有向着䁔湿方向发展的趋势, 但这种急势能维持多 久? 尚需加强监澌。

2. 近一百多年来、在暧干气候背景制导下,湖面蒸发量超过湖面降水量与人湖径流量之 和，形成湖水均衡亏损量累计值递增的韧势，这是长期以来湖水位下降的根本原因。

3. 气候的年际变化是遗成湖水位年际变化的直接原因。水位年际变化与前期降水影响 系统出现版率, 气侯类型的差异以及地面气象要素等均有密切的相关联系。

\section{考文战}

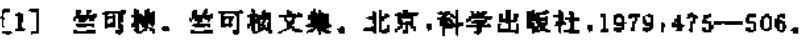

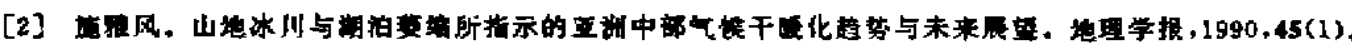

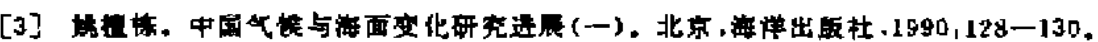

\section{DISCUSSION OF THE CLIMATIC CHANGE IN RECENT 600 YEARS AND DROPPING OF LAKE WATER - LEVEL, QINGHAI LAKE DRAINAGE BASIN}

\author{
Zhou Lusheng Yang Weidong \\ (Meterological Bureau of Qinghai Protince .Xuning 810001)
}

\begin{abstract}
The historical clunatic data sequence is reconstructed on the basis of tree ring data of Qinghai Lake Basin and reighbouring areas. In this paper four main periods (cold,warm.dry and wet " of the lake basin in the past 600 years are given and the climatic trend is predicted. It appears that the lake water-level falling is mamly caused by the warm-dry climatic tendercy in recent 100 yeais. In addition ,the relationships between the annual variation of the lake water level. the weather systems affecting antecedent precipitation , various climatic patterns and land surface meteorological elements are analyzed by means of statistical method.
\end{abstract}

Key words Qinghai Lake drainage basin, tree ring. climatic change 